\title{
Assessment of the prevailing environmental conditions: in the town of Patras, Greece with emphasis on areas with school buildings
}

\author{
Katsifara A. ${ }^{1}$ and Varnavas S.P. ${ }^{2, *}$ \\ ${ }^{1}$ Laboratory of Public Health, Medical School, University of Patras, GR - 26504, Patras, Greece \\ 2Department of Geology, University of Patras, GR - 26504, Patras, Greece \\ Received: 30/04/2018, Accepted: 10/10/2018, Available online: 15/10/2018 \\ *to whom all correspondence should be addressed: e-mail: s.p.varnavas@upatras.gr \\ https://doi.org/10.30955/gnj.002742
}

\begin{abstract}
The school buildings in and around the city of Patras in the prefecture of Achaia, Greece, are classified on the basis of the prevailing environmental conditions and the existing human activities in the surrounding area. School buildings in urban and rural environment are investigated. The type and the sources of pollutants reaching the soil or the air in the school environment, air particles and noise are considered in this investigation. A number of school buildings have been constructed near traffic roads. As a result of this, the school environment is affected by noise and air particles produced from the combustion of petrol by the vehicles. In other cases, fine particles, related to resuspension of soil of the school yard and the surrounding area, affect the school environmental conditions. Similarly, under specific meteorological conditions, some schools in the rural environment can be affected by the agriculture activities, such as the use of fungicides. Specific measures are suggested to be taken for all groups of schools for the protection of the students' and the teachers' health.
\end{abstract}

Keywords: Environment, air quality, air particles, pollution, school buildings, health, medical geochemistry.

\section{Introduction}

The city of Patras, as the third biggest city of Greece, being the capital city of the prefecture of Achaia, with the centralization of all public services and the presence of considerable commercial activity on its urban web, is assumed in this study to receive significant environmental pressure. School facilities are places where students and employees (educational staff and others) spend a great amount of their time during the day. The fact that several schools had been built before rules were legislated to take into account the prevailing environmental conditions, led to the idea to carry out this research.

The aims of this work are:

a) The geographic mapping of all school units of all levels across the city and the periphery of Patras. b) Their grouping on the basis of environmental criteria, e.g. their proximity to various human activities.

c) The assessment of the specific environmental conditions causing a pressure on the quality of the environment in the various groups of school units.

d) The suggestion of measures that can improve the quality of the school environment for the protection of the students' and the teachers' health.

\section{Methodologies}

Initially, all the school units of the city of Patras constituting the functional building stock of pre-school, primary and secondary education in the years 2014-2015 when this study was carried out, were recorded in tables after a survey work, using the Patras Municipality archives. They were then grouped according to their geographical location and the level of education they accommodate. Another criterion used was their position, examining whether they fall within the main city area or in periphery of the city. In order to achieve this the school coordinates were used to draw geographic maps showing the sites of the schools, using the Earth - graphical imaging program (Google Earth).

Thus the schools were classified into eight groups:

1A, 2A, 3A, 4A: They fall within the main city area.

1: Kindergarten 2: Primary School 3: Gymnasium 4:Lyceum

$1 B, 2 B, 3 B, 4 B$ : They fall within the periphery of the main city area.

1: Kindergarten 2: Primary School 3: Gymnasium 4:Lyceum

In addition, using the Google Earth software, aerial photographs were taken from representative school units. The examination of these photographs showed the presence of annoyances for school units, adjacent to 
certain types of human activities, as well as the general effect of the natural environment.

Furthermore, the existing research literature regarding the air quality measurements and pollutant values recorded at various stations in the city was studied. The in-depth study of these values, in relation to the hours of measurement, and the location of schools has led to useful observations and conclusions described below in regards to the effects of pollution on school environmental conditions.

Based on the premise that measurements made from studies over a number of years show a consistent pattern or presence of pollutants, it can be inferred that these prevail and affect school environmental conditions accordingly.

\section{Results and discussion}

Two hundred and twenty two school units of Patras Municipality were investigated in urban and rural environment. One hundred and twenty six of these school buildings are located in the main city area, whereas the remaining ninety six are in the periphery of the city. Environmental studies showed that the school units of urban environment are affected by air pollution. Also, schools in the rural environment can be affected by the agriculture activities.

Particles suspended in the air are an important pollutant that adversely affect the health of students and workers in those cases where these pollutants are above the upper safe values. To thoroughly examine this issue, research papers were studied concerning the dispersion of suspended particles in various areas of the city of Patras. The levels of concentration of suspended particles in the atmosphere and their areal enrichments were studied. Although suspended particles measurement stations have not been decided by the researchers to cover the whole city of Patras to examine the effect of suspended particles on school facilities, the density of existing stations at specific sites combined with the study of meteorological conditions allow conclusions to be drawn on this issue.

Studies carried out in the Municipality of Patras on the levels and variations of the concentration of suspended particles in the air, their content in toxic elements such as $\mathrm{Pb}, \mathrm{Ni}, \mathrm{Cd}, \mathrm{Mn}$, As as well as noise measurements, showed that atmospheric pollution and the noise disturbance of residents is generally high. It has also been found that the time of maximum concentrations of suspended particles in the atmosphere in the city of Patras occurs at the peak traffic hours e.g. 08:00-11:00 (Bloutsos and Yannopoulos, 2011).

It is noted that this is the time that pupils are at school and therefore protection measures can be suggested, especially during this critical period. As it is shown below, the measurements made at the existing stations, combined with the density of schools, leads to the conclusion that the above pollutants also affect the environment of some school facilities. Typical examples of the effect of atmospheric pollutants on school units, where particle count stations are next or at a short distance from them are given below.

For example in the Ellinos Stratiotou-Agias Sofias location, where there is a school unit, suspended particles were measured and a $\mathrm{PM}_{10}$ value of $54 \mu \mathrm{g} / \mathrm{m}^{3}$ was reported in March at peak traffic hours 8:00-10:00. This value is higher than the maximum safe-set value of the European Union $\left(50 \mu \mathrm{g} / \mathrm{m}^{3}\right)$. In the same month several values were measured slightly below this limit. Between the hours 13:00-15:00 at the above station in March, a much higher value $\left(149 \mu \mathrm{g} / \mathrm{m}^{3}\right)$ was measured for $\mathrm{PM}_{10}$ compared to the previously mentioned maximum value $\left(50 \mu \mathrm{g} / \mathrm{m}^{3}\right)$. On average, in May the $\mathrm{PM}_{10}$ values at Ellinos Stratiotou -Agias Sofias in the morning hours 8:00-10:00 are higher than midday hours 13:00-15:00. Similarly in the neighboring location of Ellinos Stratiotou- Ioanninon, even higher $\mathrm{PM}_{10}$ values were observed in May than March and higher values in the morning hours rather than at the traffic peak hours (Massara, 2011).

Apostolopoulou and Varnavas $(2011,2013)$ also studied fluctuations of air particle concentrations at stations in and around Patras port in relation to ship arrival times and departure times and in relation with the prevailing meteorological conditions. These studies showed that there was a marked increase in suspended particles in the air of the city of Patras at the arrival and departure hours of the ships. Considering the prevailing directions of the winds, it was concluded that a large part of the air particles was transferred to a wider part of the city of Patras. It is interesting to note that one of the measuring stations for suspended particles, where high values of suspended particles were found, was situated at a short distance from a school unit.

In addition, suspended particle measurements carried out outside the new port of Patras, showed values for $\mathrm{PM}_{10}$ suspended particles exceeding $50 \mu \mathrm{g} / \mathrm{m}^{3}\left(93 \mu \mathrm{g} / \mathrm{m}^{3}\right.$ ) (Krotsis, 2011). It is noted that a school unit exists at a short distance from the new port of Patras. Yannopoulos (2007) showed that there is a good positive correlation between average hourly concentrations of $\mathrm{SO}_{2}$ and $\mathrm{NO}_{2}$ at various stations in the city of Patras during the peak traffic hours.

This can also support a correlation of these pollutants with the noise, since both the noise and the above pollutants have a common origin. It is noted that the noise measurements made at 25 stations in the city of Patras gave high unacceptable values (Stathis, 1981). Therefore, it can be concluded that schools which receive significant pressures from suspended particles also receive significant pressure from noise.

The chemical analysis of suspended particles from various locations in the city of Patras showed the presence of As 2.5 times above the maximum admissible value given by the European Union $\left(6 \mathrm{ng} / \mathrm{m}^{3}\right)$. The metals $\mathrm{Pb}, \mathrm{Cd}, \mathrm{Ni}$, were attributed to road traffic. The source of $\mathrm{Mn}$ was considered to be the central heating of the city, as well as the ground resuspension. The main source 
of As was the use of fungicides, insecticides used for the decontamination of buildings (Bloutsos and Yannopoulos, 2011). The behavior of $\mathrm{Mn}$ in soil and its resuspension is in agreement with Kalavrouziotis et al. (2006, 2007a, 2007b, 2008) which showed that the soils next to motorways were more enriched in $\mathrm{Mn}$ in relation to locations away from the road. The resuspended soil can still contain platinum (Pt, Pd, Rh), their main source being the car catalysts. Experiments on cellular studies have shown the adverse effects of these elements on human health (Kalavrouziotis et al., 2008). Characteristics examples of schools which are affected by pollution in accordance to these findings are those located mainly at Maizonos street - Satovriandou street and Maizonos street - Trion Navarchon street.

Based on the levels of $\mathrm{SO}_{2}, \mathrm{NO}, \mathrm{NO}_{2}$ concentrations at a significant number of stations, maps were drawn showing the geographic changes of the values of the above pollutants, the source of which is attributable to road traffic (Yannopoulos, 2007). A detailed examination of the position of the schools studied here, in relation to the concentration curves of these pollutants in the city of Patras, shows that there are schools which fall within the zones of maximum or high concentrations of these pollutants. This indicates that the air quality in these school units during the winter period at which the maps were drawn is degraded.

A significant source of suspended particles in the atmosphere and the toxic metals, apart from those mentioned above, can also be the wood fires or soil resuspension, as well as the combustion of various materials in the fireplaces and the transfer of pollen by the wind (Karaberou and Varnavas, 2007; Varnavas et al., 2012; Varnavas, 1999, 2002; Varnavas, 2010; Karaberou and Varnavas, 2004). These sources have a greater impact on the school units situated in the periphery of the city, that is group $1 B, 2 B$, $3 B, 4 B$ than those located in the main city area $(1 A, 2 A$, $3 A, 4 A)$.

It is observed that some of the school units, are located next to agricultural crops, olive oil press or winery. This leads to environmental pressure on the school units derived from noise made by agricultural machinery, from spraying crops with toxic chemicals (insecticides-pesticides). It is important to note that fungicides used are likely to contain mercury $(\mathrm{Hg})$, which is extremely toxic. Mercury is volatile, affecting the central nervous system of human beings.

Neighboring environments with school units in this group, such as marshes are characterized by the presence of mosquitoes which affect the pupil's health. Also certain types of adjacent installations, such as for storage of building materials, contribute to the dispersion of suspended particles with toxic components.

According to the above results, a suggestion of suitable measures which can improve the quality of the school environment for the protection of the students' and the teachers' health is essential.

\section{Conclusions-proposals}

1. In this work, it is shown that the schools of the Municipality of Patras in Greece can be classified according to environmental criteria into two main categories, which reflect the association of geographical location and environmental conditions: those that fall within the main city and those that fall according to their location in the periphery of the city.

2. For the first category which concerns schools in the main city, the major source of pollutants which degrade the air quality at schools, is road traffic. The main pollutants are suspended particles, $\mathrm{SO}_{2}, \mathrm{NO}, \mathrm{NO}_{2}, \mathrm{CO}$, toxic metals such as $\mathrm{Pb}, \mathrm{Cd}, \mathrm{Ni}$ and hydrocarbons.

3. An examination of measurement data given by several researchers at various stations across the city for the above pollutants, showed values for certain pollutants above the safe values given by the European Union.

4. The times of peaks found for the suspended particles concentration in the atmosphere coincides with the traffic peak hours 08:00-10:00.

5. It is suggested that we must inform the local school principals and education authorities about the hours of maximum presence of pollutants in the atmosphere, so as to take measures to protect the pupils. For example, the school timetable may be modified, so that the pupils are not in the school yard between 08:00-10:00. This can also be taken into account in the preparation of Physical Education course, where this lesson takes place in the school yard. This can also be taken into account for other activities, taking place in the school yard.

6. The positive correlation found between concentrations of $\mathrm{SO}_{2}, \mathrm{NO}, \mathrm{NO}_{2}$ and road traffic rate at peak hours corresponds to an increase in noise. Noise measurements gave values above the acceptable as safe values.

7. The chemical analysis of suspended particles, showed in various locations 2.5 times higher values of As than the higher value acceptable as safe by the European Union $\left(6 \mathrm{ng} / \mathrm{m}^{3}\right)$. The main source of As was considered to be the use of insecticides for buildings decontamination.

8. Central heating was considered to be the source of metals $\mathrm{Pb}, \mathrm{Cd}, \mathrm{Ni}$, detected in suspended particles, whereas the source of $\mathrm{Mn}$ was the soil resuspension.

9. Due to soil resuspension the atmospheric air can be enriched through the wind with $\mathrm{Pt}, \mathrm{Pd}, \mathrm{Rh}$, which originate from car catalysts.

10. Measures are proposed to improve environmental conditions at school units such as the planting of suitable tree species between the road and the schoolyard. 
11. For the prevention of noise it is possible to install a special noise barrier.

12. At school units where the yard is made of a fine ground for the purpose of preventing the dispersion of fine dust special phytostats may be planted (e.g. the Festuca arudinaceae species).

13. Where school units are neighboring with cultivated lands, if spraying takes place there is a need to take special measures to protect pupils and employees.

\section{Acknowledgements}

We would like to thank the Municipality of Patras for the generous provision of the catalogs with the school units of the Municipality as well as the environmentalist Mr. Zois Spiliopoulos of the Region of Western Greece for the useful discussions and information on the subject of this project. In addition, we would like to thank an anonymous reviewer for his/her valuable suggestions improving the original manuscript.

\section{References}

Apostolopoulou K. and Varnavas S.P. (2011), Air pollution in the town of Patras, Greece related to maritime transport and port activities, Proceeding of the 12th International Conference on Environmental Science and Technology, Rhodes Greece 8-11, 2011, A94-102.

Apostolopoulou K. and Varnavas S.P. (2013), An investigation of the air quality above Patras, Greece port in relation to the arrival and departure schedule of the ships, 13th International Conference on Environmental Science and Technology (CEST, 5-7 September 2013, Athens).

Bloutsos A.A. and Yannopoulos P.C. (2011), Concentrations of selected toxic elements in airborne particulates of Patras, Greece, Global NEST Journal, 13, 109-118.

Kalavrouziotis I.K, Carter J., Varnavas S.P., Mehra A. and Drakatos P.A. (2006), Towards an understanding of metal contamination in food crops and soils related to road traffic, Fresenius Environmental Bulletin, 15, 170-175.

Kalavrouziotis I.K., Jones P., Carter J. and Varnavas, S.P. (2007), Uptake of trace metals by Lycopersicum esculendum L. at a site adjacent to the main road Athens - Thessaloniki, Greece, Fresenius Environmental Bulletin, 16, 133-139.

Kalavrouziotis I.K, Carter J., Varnavas S.P., Mehra A. and Drakatos P.A. (2007B), Towards an understanding of the effect of road pollution on adjacent food crops: Zea mays as an example, International Journal of Environment and Pollution, 30, 576-592.

Kalavrouziotis I.K. and Koukoulakis P.H. (2009), The Environmental Impact of the Platinum Group Elements (Pt, $\mathrm{Pd}, \mathrm{Rh})$ Emitted by the Automobile Catalyst Converters, Water, Air, and Soil Pollution, 196, 393.

Karaberou G. and Soterios S.P. (2004), Investigation of the Possibilities in Reduction of Environmental Effects from Industrial Wood Processing for the Production of Paper, 1st Greek conference, Green Chemistry, February, Athens, Greece.

Karaberou G. and Varnavas S.P. (2007), Wood Industrial Activities as Major Metal Contaminant Sources, 2nd National Congress on Green Chemistry, March 2007, Patras.
Krotsis S. (2015), Time Series Analysis of Air Particles in the Area of the Port of Patras, Greece, MSc Dissertation, Hellenic Open University.

Massara B. (2011), Suspended Particles in the Patra's Atmosphere, MSc Dissertation, University of Patras.

Stathis Th.C. (1981), Community noise levels in Patras, Greece, The Journal of the Acoustical Society of America, 69, 468.

Varnavas S.P. (1999), Nutrition and inorganic world: Unawareness or a trend to self-destruction, Proceeding of Conference on Environmental Science and Technology, University of Patras, pp. 1-12.

Varnavas S.P. (2002), The contribution of Geochemistry in the assessment of environmental conditions in soil and water systems and in the application of methodologies for land remediation, Bulletin of Geological Society of Greece, 34, 2207-2217.

Varnavas S.P. (2010), Medical geochemistry, a key in the precautionary measures against the development of cancer and other diseases, Bulletin Geological Society of Greece, XIIII, 234-246.

Varnavas S.P., Kalavrouziotis I.K., Karaberou G., Apostolopoulou K. and Varnavas P.S. (2012), Medical geochemical investigations in taking precautionary measures against diseases. Protection of human health, Global Nest Journal, 14, 505-515.

Vissisky V.A., Stepashko V.S., Kalavrouziotis I.K and Varnavas S.P. (2008), The road pollution impact on Zea mays: Inductive modeling and qualitative assessment, Water, Air and Soil Pollution, 195, 301-310.

Yannopoulos P.C. (2007), Spatial concentration distributions of sulfur dioxide and nitrogen oxides in Patras, Greece, in a winter period, Environmental Monitoring and Assessment, 135, 163-180. 